\title{
SIPOC MODEL IN MOROCCAN ENGINEERING EDUCATION CONTEXT: LEAN APPROACH
}

\author{
Amine HADEK, Hind CHAIBATE, Soumia BAKKALI, Souad AJANA \\ Team of research in engineering education Engineering research laboratory ENSEM- \\ Hassan II University of Casablanca, Morocco
}

\begin{abstract}
Morocco country faces a set of challenges related to the global economic crisis which strongly affects the funding dedicated to different development sector. In this way, engineering schools are expected to respond to higher education's heightened requirement while using the minimum amount of resources. Lean thinking is a systematic approach to improve the efficiency of the educational process by promoting continuous improvement. It can be applied both to learning and administrative steps to eliminate activities that do not add value. In order to apply lean thinking principles in Moroccan engineering education we need to understand how process activities create value and interact together. The process approach is a powerful way of visualizing process flow and how inputs are transformed into outputs using different resources. The purpose of this study is to introduce the first two principles of lean thinking, namely value definition and process mapping, in Moroccan engineering education. Firstly we have chosen to study the ENSEM (National Higher School of Electricity and Mechanics) processes. We have described its learning system in order to define the value and elaborate the macro process mapping. Thereafter, we have built SIPOC process map in the ENSEM context.
\end{abstract}

\section{KEYWORDS}

Lean thinking, Moroccan engineering education, Lean principles, ENSEM, Value, macro process mapping, SIPOC.

\section{INTRODUCTION}

Moroccan engineering education faces challenges around delivering high performance while using available resources. This sector is full of unnecessary and non-value added activities that should be eliminated or at least reduced to accomplish high level of efficiency and effectiveness. In this way, there is an evident need for engineering schools to adopt optimization and continuous enhancement strategies to improve the services delivered to students, staff and other external partners [1].

Lean is an improvement approach that aims at developing new ways of working and standardizing the best practices. It is about how people within the process interact together in order to build a culture of work based on continuous improvement and respect for people. Lean can be applied to enhance administrative and learning processes [2].

Although many feedbacks and results have been accumulated on the profitability of implementing lean thinking principles and tools in different Moroccan enterprises; no published studies are available on how to benefit in concrete terms from lean thinking strategies to improve educational performance. 
This study aims to fill this gap and to present a case study by implementing lean thinking principles and tools at a Moroccan engineering school. For this reason we have studied the ENSEM (National Higher School of Electricity and Mechanics) educational system. We have defined the value and elaborated the process map in the ENSEM context.

\section{LITERATURE REVIEW}

\subsection{LEAN THINKING KEY SUCCESS}

In order to drive effective lean initiative 3 keys success must be present:

-Prepare environment for transformation: Before thinking how to implement lean principles, lean team and even the whole organization should be prepared for the change. The major challenge here is to deal with human resources [3]. Everyone on the process must understand the reasons behind this change to ensure engagement of all the members. Academic and non-academic staff should learn how to implement lean principles by conducting learning and sensitization sessions.

-Lean culture: engineering education schools should adopt a lean culture where all stakeholders are allowed to give suggestions and solutions [4]. In this transformation, manpower is a precious resource able to make successful decision.

-Performance measurement: It is important to measure the level of performance progressively to the change by choosing an efficiency indicator that should be continually updated. This step is crucial in any change because it materialize achieved results in order to determine progress in comparison to the objective [3].

To achieve successful results it's important to start lean implementation with a small process and then expand the approach to other processes or departments.

\subsection{LEAN THINKING STEPS}

Lean thinking is a systematic approach to improve organization's efficiency and quality of outputs by reducing lead times and liberating resources to promote growth and competitiveness. It is based on fives principles: value identification, value stream mapping, flow creation, pull establishment, pursuit of perfection. Figure 1 summarizes all these principles. 


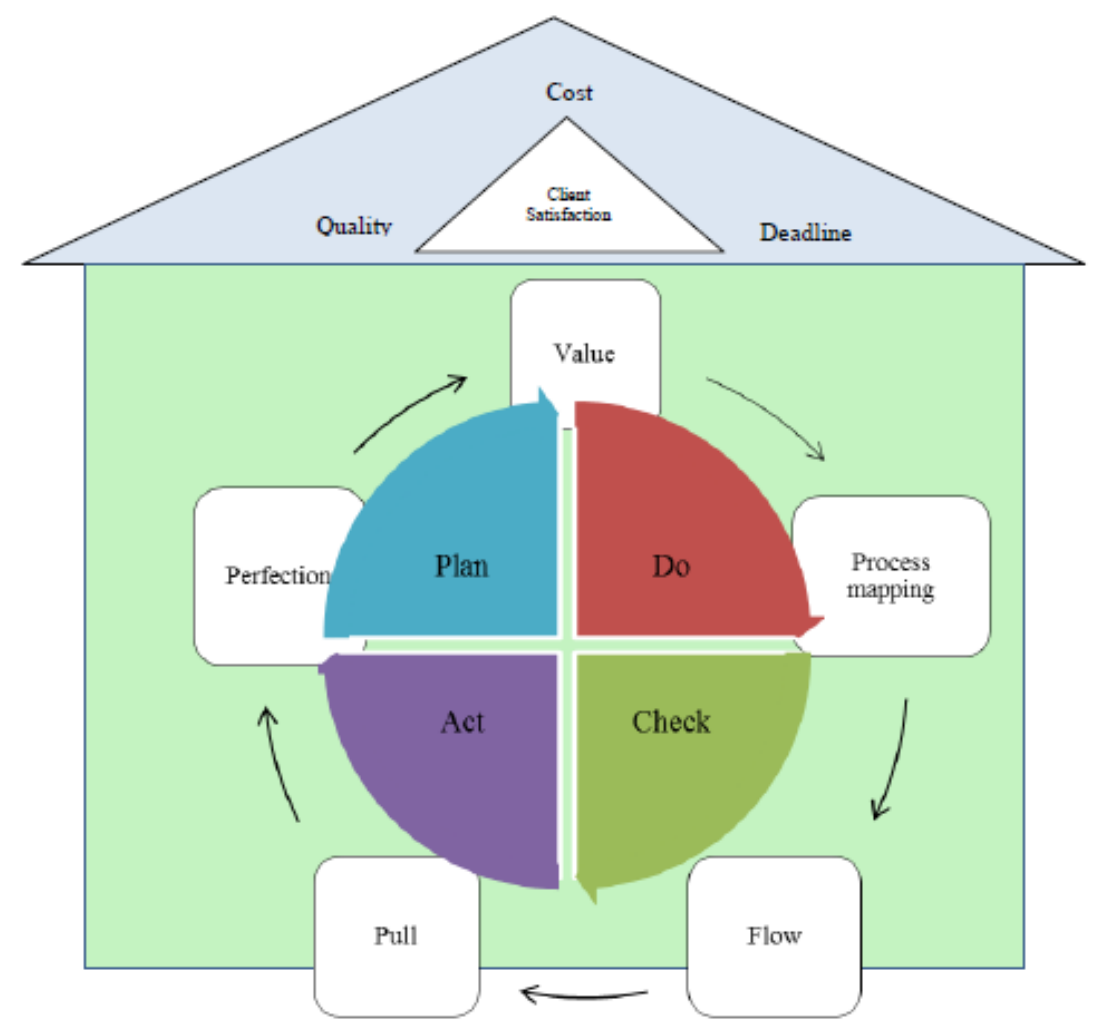

Figure 1. Lean thinking principles

- Value: value is defined from the point of view of the end customer, it's is everything that he is ready to pay for [5]. The use of Brainstorming or other quality tools can enable organizations to define exactly what the customer sees as value

- Map the value stream: a value stream map identifies all the steps, processes, and resources necessary to produce and deliver a good (product, services) to customers [5]. It enables organization to reveal time delays and all activities that don't create value to make serious efforts to eliminate them

- Create flow: flow is a sequence of steps and activities that create value without anything that can interrupt the flow of value [6]

- Establish pull: Produce what is actually needed by customer without overproduction [6], this means start an activity only when there is a demand for it and according to customer requirements (cost, time, quality)

- Seek perfection: The main objective of lean thinking approach is pursuit of perfection by adopting strategies and technics that promote continuous improvement. The latter can be achieved particularly by applying quality tools such as Plan-Do-Check-Act known as PDCA cycle, capitalizing best practice and standardizing processes that are subject to human error [7]. 


\section{Higher EduCATION In Morocco 3.1. HIGHER EDUCATION DEGREES}

Higher education in Morocco is regulated by Statute No 01-00. The latter consolidates the educational, financial and administrative autonomy of universities by establishing a system for courses accreditation and institution audit. The public higher education includes the system for the training of future executives falling within the responsibility of specialized ministries and the university system which fall under the responsibility of the Ministry of National Education, Higher Education, Executive Training and Scientific Research [8, 9]. The system of higher education is divided into three degree:

- Bachelor degree: it lasts for three years after the final school exam (baccalauréat), it include two years of undergraduate diploma in general studies (DEUG) or in vocational studies (DEUP) and one year of the bachelor degree in basic studies or the vocational Bachelor degree that is provided in universities and in higher technology schools (Écoles Supérieures de Technologie).

- Master degree: it lasts for two years after the Bachelor degree in basic or applied disciplines.

- Doctorat degree: it lasts for three years after the master degree, the specialized Master degree or an equivalent diploma.

\subsection{RESPONSIBILITIES}

The ministry of higher education elaborates and implements government policy in the area of higher education and scientific research and ensures its application in partnership with the ministries concerned. It is also responsible for coordinating and evaluating the activities of higher-education institutions for training future executives. It supervises private higher education institutions. During the Conference of University Presidents the heads of universities discuss all issues concerning public higher education, coordinate universities activities and exchange experiences related to cooperation and good governance $[8,9]$.

Universities are governed by Presidents who are assisted by vice-presidents in charge of international cooperation and scientific research. Each university has a Governing Board (Conseil d'Université) composed of the Dean, the heads of department and elected members. The Presidents are appointed by the King after a call for applications. The Deans of each faculty and the heads of schools are appointed following a call for applications $[8,9]$.

\subsection{FINANCING}

Public higher education in Morocco is free of charge. The state budget covers universities investment and operating costs depending on the number of enrolled student in each institution. University financing resources are composed of state subsidies, enrollment fees, scientific research, service delivery, donations, and any profits generated by other operations authorized by the law. Institutions with restricted access such as engineering schools receive additional funding than those with unrestricted access [11].

\subsection{QUALITY ASSURANCE AND ACCREDITATION}

According to the Statute No 01-00, all programs leading to a national diploma at public institutions should be accredited. Accreditation is also awarded to private high education programs. It is granted by department of higher education in the ministry after having the view of 
International Journal of Education (IJE) Vol.7, No.1, March 2019

the National Coordination Commission of Higher Education (Public University Higher Education Institutions), the Coordination Commission for Private Higher Education and the Coordination Council of non-University Higher Education Institutions. The National Accreditation and Evaluation Committee, placed under the authority of the ministry of higher education, is the last instance that recommends accreditation granting or demand rejection [12]. The accreditation process consists of the following steps:

- Elaboration of accreditation documents (description of the accreditation request, evaluation guide, and evaluation charter)

- Presentation of the accreditation request by universities

- Evaluation of the accreditation request by two experts supervised by the sub-commission coordinator of the concerned field

- Examination of the sub-commission proposals by the National Accreditation and Evaluation Committee

- Decision of the ministry on the basis of the National Accreditation and Evaluation Committee opinion

\subsection{Moroccan EngineEring EduCATion}

\subsubsection{Types of engineering institutions}

Engineering schools are classified in two categories:

- Engineering institutions affiliated to universities under the supervision Ministry of Higher Education, Scientific Research and Executive Officer Training.

- Engineering institutions affiliated to technical ministries supervised by the Ministry of Higher Education, Scientific Research and Executive Officer Training

\subsubsection{Admission}

In order to access to the first year of an engineering career, students having successfully passed the national competition of preparatory classes [13] or students holding an equivalent qualification must succeed in an open competition. Students having a bachelor degree or equivalent can also integrate the second year of an engineering training. Some engineering schools have an integrated preparatory cycle and Candidates are selected according to the marks obtained in their baccalauréat.

\subsubsection{Curriculum content}

Engineering courses last for three years (6 semesters) after preparatory classes ( 2 years after the baccalauréat) or another equivalent career. Curricula must respect the educational standards (cahier des normes pédagogiques) where the first five semesters are devoted to educate three kinds of courses [14]:

- Technical modules composed of basic and scientific courses related to the specialty of engineering degree. They represent between $60 \%$ and $80 \%$ of the overall hours of the first five semesters.

- Managerial modules aim at teaching management principles to undergraduates and improving their initiative spirit. They represent between $10 \%$ and $20 \%$ of the overall hours of the first five semesters. 
- Language and communication modules represent an opportunity to improve students' communication skills. They represent between $10 \%$ and $20 \%$ of the overall hours of the first five semesters.

The sixth semester is dedicated to the final year project that should be defended before jury members.

\subsubsection{Cooperation school- enterprise}

Morocco is more aware of the importance of involving the job market in scientific research and courses design in order to ensure alignment between training and employers requirements. The cooperation school-company is achieved through the company traineeship scheduled each year especially the last year where it lasts for 6 months. The international cooperation plays a relevant role in facilitating students' mobility and staying competitive in the global market $[8,9]$.

\section{LeAn Thinking At MorocCan Engineering EduCATION \\ 4.1. Case study \\ 4.1.1. Presentation of the ENSEM engineering school}

In this study we will show how lean thinking can be rolled out at a Moroccan engineering school (National Higher School of Electricity and Mechanics (ENSEM)). The latter is a public and French-speaking institution, under the aegis of the Hassan II university .It works towards advancing engineering education and research in four broad areas: mechanical engineering, electrical engineering, industrial engineering and computer engineering.

Established in 1986, the school is still trying to enhance its performance and promote continuous improvement. ENSEM provides its students with a variety of facilities such as accommodation, refectory, and health services. Campus is within short walking distance of the teaching rooms.

ENSEM provides two kinds of training:

- Initial training: it includes engineering degree and doctorate degree

- Continuing training: it includes professional bachelor degree and specialized master degree

In our study we will be especially interested in the engineering degree.

\subsubsection{Admission to ENSEM}

Admission to the ENSEM School of Engineering is selective. Figure 2 details the admission process. 
International Journal of Education (IJE) Vol.7, No.1, March 2019

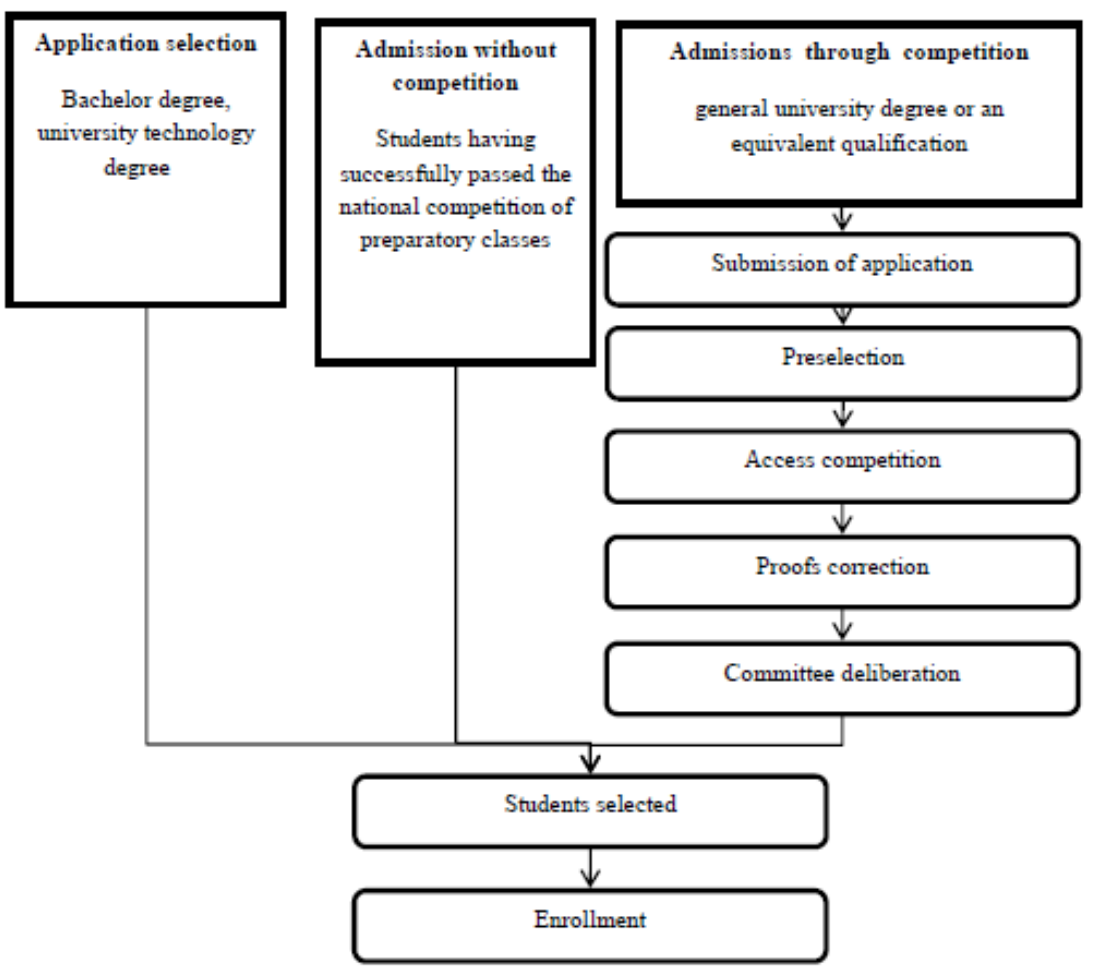

Figure 2. ENSEM's engineering admission process

Students may be admitted to an engineering degree program as freshmen (first year) students. Admissions for students holding a bachelor degree or a university technology degree are selective. Demands are judged on several factors, such as academic record at high school and university level. Students having successfully passed the national competition of preparatory classes are directly selected to integrate the school's courses. Students having a general university degree or an equivalent qualification must succeed in an open competition [10].

\subsubsection{Staff and services at ENSEM}

The work of management staff is divided into the activities around planning, leading, organizing and controlling. It is also responsible for managing quality assurance programs, researching new strategies to improve school's efficiency and setting budgets and managing cost. Figure 3 presents the ENSEM's organizational structure. 


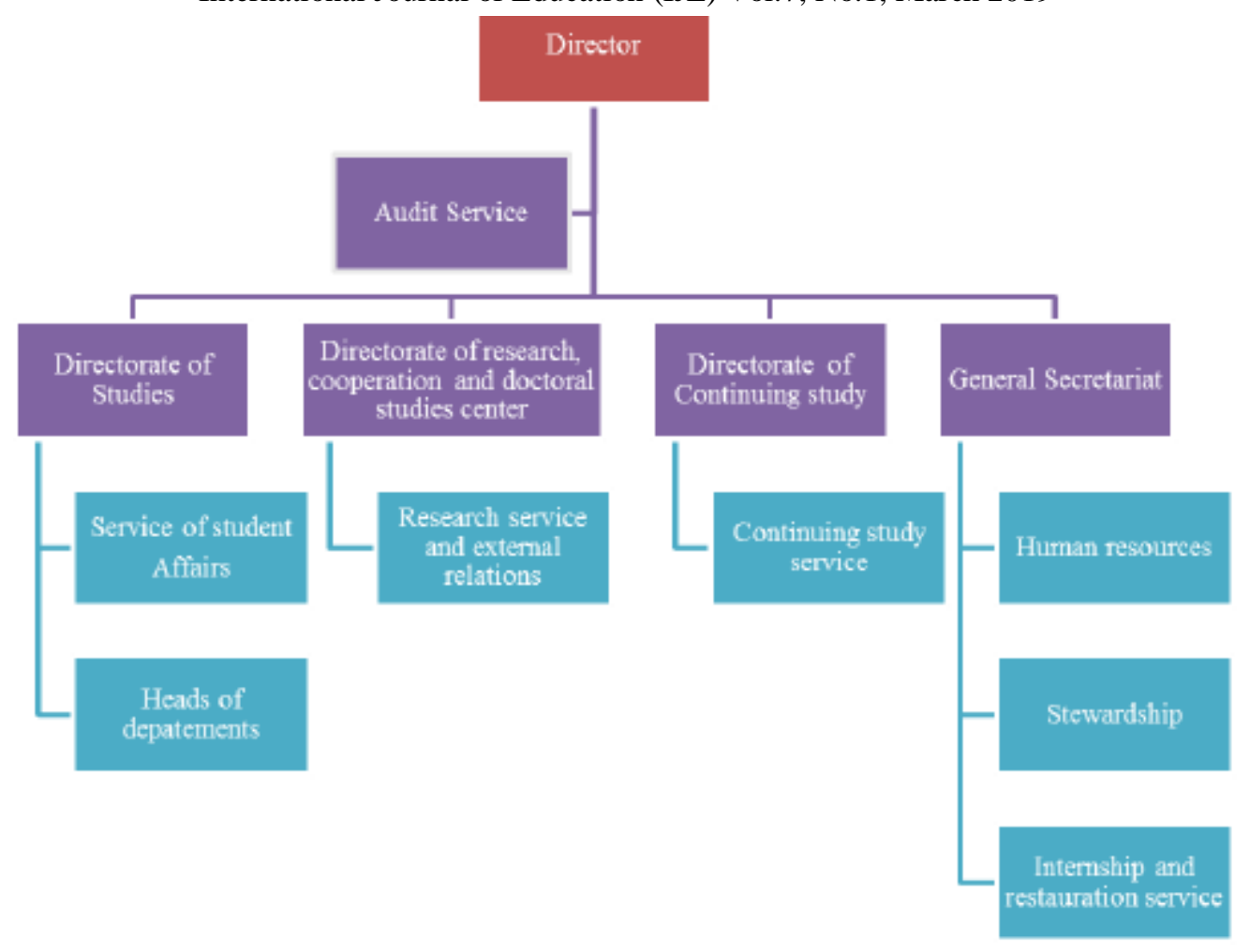

Figure 3. ENSEM's organizational structure

ENSEM management staff is composed of the head of institution, the audit service, the directorate of studies, the directorate of research, cooperation and doctoral studies center, the directorate of continuing training and the general secretariat that is related to the human resources' service, the stewardship service and the internship and restoration service.

The academic staff comprises Professor of Higher Education (Professeur de l'Enseignement Supérieur (PES)), professors entitled to supervise a thesis (professeurs habilité), assistant professors (newly recruited teachers), and associated professors (teachers recruited temporary to teach a specific subject (vacataires)). Doctoral students are initiated to teaching practice by providing some courses training; they also participate in supervising exams.

\subsection{VALUE IN THE ENSEM CONTEXT 4.2.1. Quality definition}

Quality can be defined in the engineering education context as the ability to meet the beneficiaries' requirements $[15,16]$. It can be ensured if a quality approach is applied to all the educational processes such as teaching, evaluation, and resources management.

Lean thinking is a quality management approach, which can be deployed to improve the engineering education field [17]. The motivation for engineering schools to apply lean thinking is to ensure that staff members had the necessary tools and methods for improving the services delivered to different customers (student, staff, industry partners, universities...) and reducing the administrative overhead. 


\subsubsection{Customers identification}

Students can be seen as customer, raw material and product from different perspectives [18, 19, 20]. Students intend school in order to develop a set of skills and abilities, they are considered as the immediate internal customer of the teachers in the classroom. On the other hand, students go through a number of courses to be converted into the final product called engineering graduates to meet employer's needs.

If engineering institutions want to ensure the quality of their services, they must devote considerable efforts to understand their customers' needs. In this context, customers can internal or external to the institution [21]. Table 1 identifies the relevant customers of engineering education and their corresponding requirements.

Table 1. Customers of engineering education

\begin{tabular}{|c|c|c|}
\hline & Customers & Needs \\
\hline \multirow{5}{*}{ Internal customers } & Students & $\begin{array}{l}\text {-Develop the technical and managerial skills } \\
\text { needed by employers } \\
\text {-Benefit from good school facilities: dormitories, } \\
\text { refectory, sports activities, healthcare, security, } \\
\text { libraries, access to internet }\end{array}$ \\
\hline & Lecturer (teachers) & $\begin{array}{c}\text {-Respect recognition and good compensation } \\
\text {-Autonomy and adequate educational materials } \\
\text { and supports } \\
\text {-students with the necessary prerequisite for } \\
\text { course elaboration } \\
\text {-Opportunities for career growth } \\
\text {-School facilities : sport activities, bookstores, } \\
\text { libraries, security }\end{array}$ \\
\hline & Departments & $\begin{array}{c}\text {-Cooperation, collaboration and communication } \\
\text { between departments }\end{array}$ \\
\hline & Non-academic staff & $\begin{array}{c}\text { Good work conditions (compensation, security, } \\
\text { career growth, personal development, } \\
\text { recognition, active involvement in school } \\
\text { strategies) }\end{array}$ \\
\hline & Administrators & $\begin{array}{l}\text {-Respect, recognition and appropriate } \\
\text { compensation for their works } \\
\text {-Support and suggestions from all stakeholders of } \\
\text { the institution to elaborate management strategies } \\
\text { and face difficult challenges }\end{array}$ \\
\hline \multirow{3}{*}{$\begin{array}{l}\text { External } \\
\text { customers }\end{array}$} & Employers & $\begin{array}{c}\text { Qualified engineers who have technical and } \\
\text { managerial skills, a good spirit of lifelong } \\
\text { learning and can be easily integrated in their } \\
\text { workstation }\end{array}$ \\
\hline & Schools and universities & $\begin{array}{l}\text { Engineers with a set of research skills and } \\
\text { abilities such as autonomy, critical thinking, } \\
\text { problem solving, perseverance, initiatives }\end{array}$ \\
\hline & Community & $\begin{array}{c}\text { Contribution to economic growth by filling the } \\
\text { skills gap } \\
\text { Contribution to social development by promoting } \\
\text { social mobility } \\
\text { Responsiveness of engineering school to } \\
\text { governmentalstrategies } \\
\text { Institutional autonomy } \\
\text { Education of future leaders, engineers, decision } \\
\text { makers and good citizens }\end{array}$ \\
\hline
\end{tabular}




\subsection{Process mapping 4.3.1. Process mapping levels}

Process map is a powerful method to visualize activities and steps required to provide or to develop a product or a service. In this way, a process is seen as a set of activities that require resources (material, human, funding, data, energy, etc.) to convert inputs into outputs trending towards satisfying customer needs. Process map should be created in a way to be easily understood by different stakeholders. We can have recourse to it for many reasons:

- It enables stakeholders to understand their missions and contribution in the process

- It can be used as a training tool for new recruit

- It helps decision-makers to easily identify process dysfunctions

- It can help users to find new ideas for the process improvement

According to the level of detail on a process map we can distinguish between three kinds of process maps: macro process map, process map, micro process map [22]

- Macro process map, called the Level 1 Map, it illustrates major steps of the process by giving minimal details. It can be used to understand how the product or service is provided or built in a global context.

- Process map, called the Level 2 Map, It's created from the point of view of the worker. This map details each macro process into a coordinated sequence of processes.

- Micro process map, called the Level 3 Map, it shows inputs, outputs, and steps required to perform a process. It is a necessary map to improve process performance because it gives a clear vision about value creation.

\subsubsection{Types of process mapping}

Process mapping is a relevant step to understand the behavior of the process and find ways for improving quality [22]. For now we just want to introduce briefly three principal types of process maps, we will study them in detail in the case study during this work:

- Linear Flow Process Map: is a basic and simple process map that presents the process flow in sequence of steps. It's a starting point for the process mapping.

- SIPOC "Supplier -Input -Process -Output -Customer" Process Map: SIPOC stands for Supplier-Input-Process-Output-Customer; it is a mapping diagram that gives a brief overview of the process flow. It can be used after either a level 1 or level 2 map because it enables to collect more information about the process in conjunction with its relevant parts inputs, outputs, customers, and suppliers.

- Value stream mapping: is a graphic tool for visualizing, in great detail, all the steps required to bring a product to the customer. It's a powerful way to construct the micro process map. It is especially useful to understand many performance data and identify process wastes in order to make improvements to the process.

\subsection{ENSEM'S PROCESS MAPPING}

In this paper we will elaborate the macro process map, the linear flow process map and the SIPOC process map of ENSEM in collaboration with the management staff. During a brainstorming session, team members often fill all the necessary map parameters. The value stream map requires in-depth study of process steps to identify the micro processes and their performance data. This study step will be described in future works. 


\subsubsection{Macro process map}

The structure of the ENSEM school is characterized by a number of interrelated and interacting processes, which transform inputs (engineering student) into outputs (engineers). Figure 4 describes ENSEM's engineering macro process mapping.

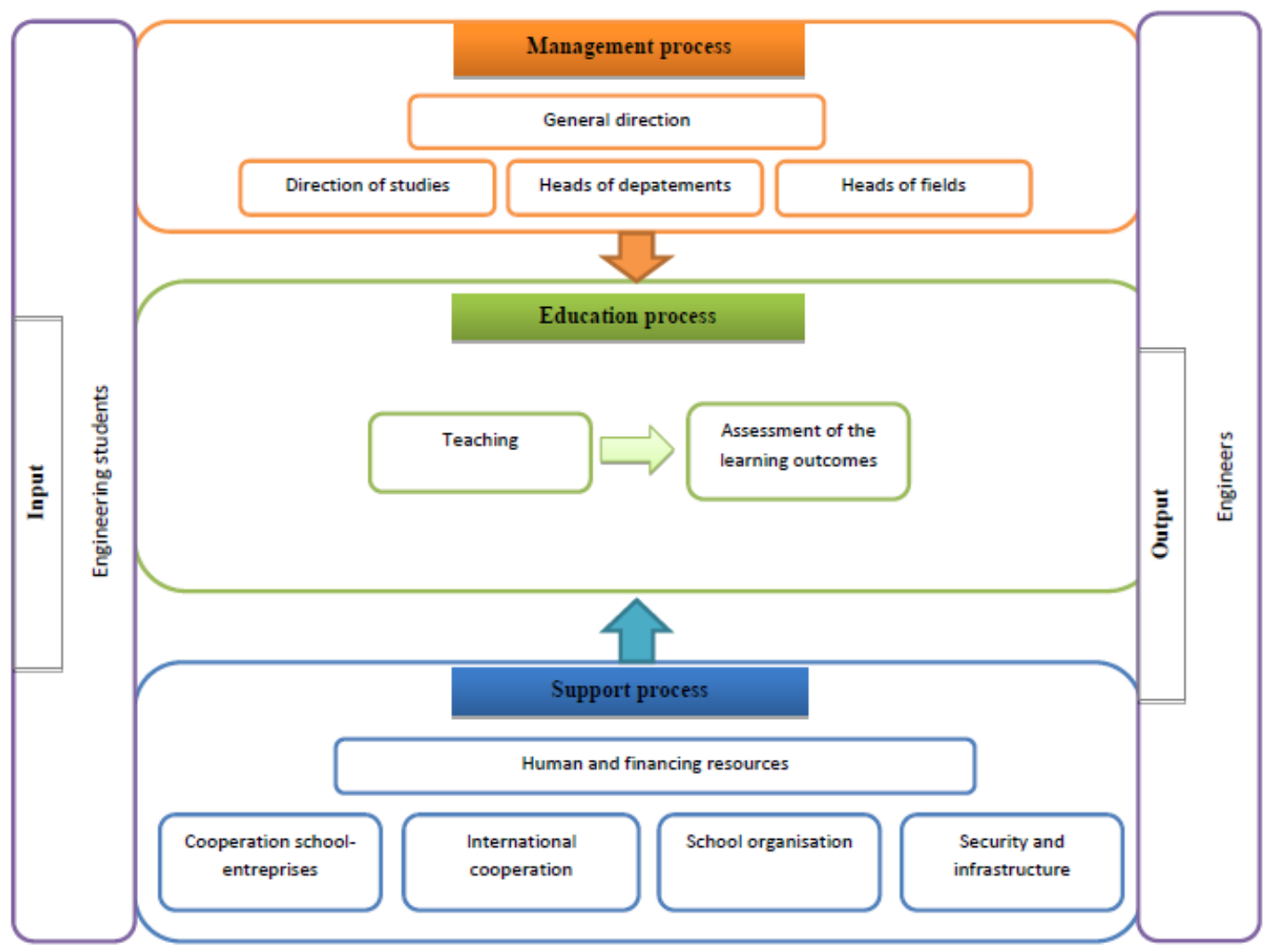

Figure 4. ENSEM's engineering macro-process mapping

ENSEM's macro processes can be classified into the following types:

- Management process: it includes processes relating to strategic planning, objectives setting, curriculums definition, and courses accreditation. This process is supported by the general direction, the direction of studies, the heads of departments, and the heads of field.

- Education process: in accordance with the accreditation standards of each engineering field, the school identifies the need for teachers and manages its educational resources. On the other hand, selected students complete their enrolment and registration procedures in order to attend the training sessions. After that students go through the assessment process to be graduated and obtain the engineering degree.

- Support process: It includes all the processes that ensure the availability of the resources required for the achievement of the objectives of the school, such as human and financing resources management, cooperation school-enterprise, international cooperation 


\subsubsection{SIPOC process map}

The acronym SIPOC stands for Suppliers, Inputs, Process, Outputs and Customer. It is a visual tool used to identify all relevant elements of a process from beginning to end. In order to construct a SIPOC diagram there are 5 steps [23]:

- Identify the process to be studied describe briefly it's key steps by drawing a simple flowchart without going into too much details (The training process, the engineers assessment process)

- Identify the key outputs of the process (The engineering schools provide skilled engineers, statistics on their laureates, scientific knowledge)

- Identify the costumers or the people who benefit from the process (The student is the schools customer, and the employer is the schools customer)

- Identify the inputs required to start the process

- Identify the suppliers of the inputs

\subsubsection{ENSEM's SIPOC model}

The first step to understand the process variables and implement lean tools is to construct a process map for engineering education. The latter, starts with supplying raw materials (inputs) and ends with delivering outputs to the customer. Figure 5 illustrates a version of SuppliersInputs-Process-Outputs-Customers (SIPOC) diagram from the engineering education perspective.

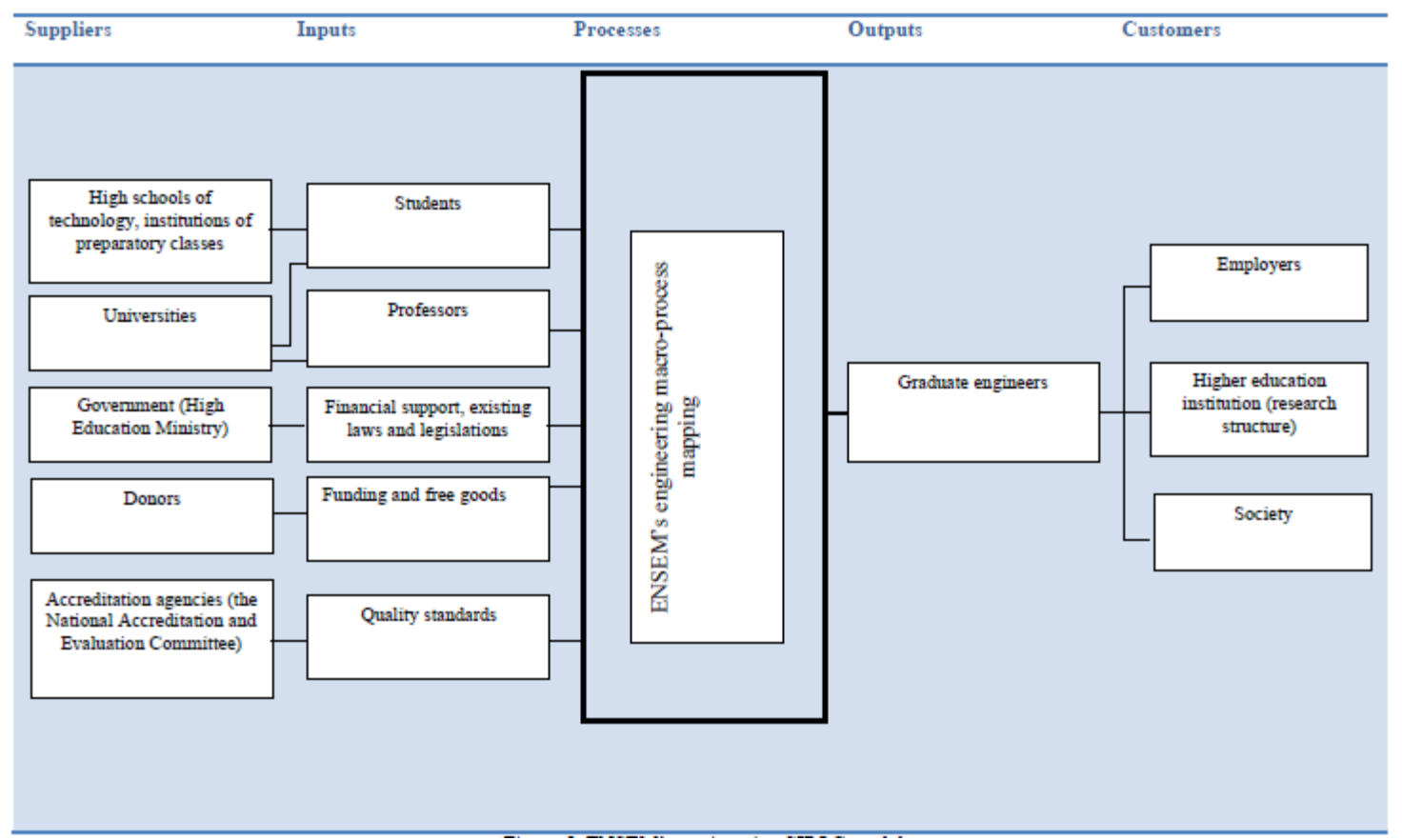

Figure 5. ENSEM's engineering SIPOC model

In this SIPOC model students are seen as raw materials which will be converted into outputs called engineering graduates. EE has a number of complementary customers as mentioned above in table 1. Suppliers refer to all stakeholders that provide the necessary process Inputs. The potential suppliers of engineering education are educational institutions such as universities, high schools of technology, and high schools of preparatory classes. The input consists of new first year student, teachers, and transfer students. Suppliers are listed in the suppliers' column and the same for other SIPOC elements. 
International Journal of Education (IJE) Vol.7, No.1, March 2019

The elaboration of ENSEM's SIPOC diagram has enabled us to identify the key processes of ENSEM. The latter will be deeply studied in order to establish the ENSEM's value stream mapping and identify non value added activities.

\section{CONCLUSION}

Moroccan engineering schools can meet the challenge of doing more with less by applying lean thinking approach. The latter is a quality improvement strategy based on continuous improvement and respect for people. In this study we have defined lean principles in a Moroccan engineering school context. Firstly we have described higher education in Morocco (degrees, responsibilities, financing, quality assurance and accreditation) especially engineering training (admission, curriculum content...). Moreover, we have defined value as the ability to meet the requirements of school's beneficiaries (students, teachers, non-academic staff, administrators, employers, schools, universities, community). In order to understand the ENSEM process we have construct the macro process map including the execution process, the education process and the support process. Finally, we have elaborated the SIPOC process map that provides more information about the process in relation with its relevant parts inputs, outputs, customers, and suppliers.

Following to this work, we will elaborate the value steam mapping that need a deep study of each process in order to define and eliminate wasteful activities and promote continuous improvement.

\section{REFERENCES}

[1] Yorkstone, S. (2016). Lean universities. In Netland, T. \& Powell, D. J. (Eds.). The Routledge Companion to Lean ManagementTaylor \& Francis (Routledge). ISBN 978-1138920590

[2] Balzer, W. K. (2010). Lean higher education: Increasing the value and performance of university processes. CRC Press.

[3] Comm, C. L., \& Mathaisel, D. F. (2005). A case study in applying lean sustainability concepts to universities. International Journal of Sustainability in Higher Education, 6(2), 134-146.

[4] Mann, D. (2014). Creating a lean culture: tools to sustain lean conversions. CRC Press.

[5] Chhatrawat, M. R., \& Dixit, M. A. (2016). LEAN PRODUCTION SYSTEM: A REVIEW. Development, 3(3).

[6] Bateman, N., Hines, P., \& Davidson, P. (2014). Wider applications for Lean: An examination of the fundamental principles within public sector organisations. International Journal of Productivity and Performance Management, 63(5), 550-568.

[7] Pârv, L. (2017). Continuous improvement processes using Lean Management tools. A case study. In MATEC Web of Conferences (Vol. 94, p. 06016). EDP Sciences.

[8] Education, Audiovisual and Culture Executive Agency (EACEA), Morocco National Erasmus+ (2017). Overview of the Higher Education System (Morocco): https://eacea.ec.europa.eu/sites/eaceasite/files/countryfiches_morocco_2017.pdf

[9] Education, Audiovisual and Culture Executive Agency (EACEA), European commission Tempus. Higher education in Morocco (2010): http://eacea.ec.europa.eu/tempus/participating_countries/reviews/morocco_review_of_higher_educati on.pdf

[10] Ecole Nationale Supérieure d'Electricité et de Mécanique. URL : https://www.ensem.ac.ma 
International Journal of Education (IJE) Vol.7, No.1, March 2019

[11] Bougroum, M., \& Ibourk, A. (2011). Access and equity in financing higher education: The case of Morocco. Prospects, 41(1), 115.

[12] MENESFCRS [Ministère de l'éducation nationale, de l'enseignement supérieur, de la formation des cadres et de la recherche scientifique]. Rapports d'activité [Activity reports].

[13] Ministère de l'enseignement supérieur de la recherche scientifique et de la formation des cadres, Concours National Commun 2016 (CNC) d'Admission dans les Établissements de Formation d'Ingénieurs et Établissements Assimilés. [En ligne]. URL : https://www.enssup.gov.ma/sites/default/files/CNC/2016/02/2839/NoticeCNC2016_12-02_12h10.pdf

[14] MENESFCRS [Ministère de l'éducation nationale, de l'enseignement supérieur, de la formation des cadres et de la recherche scientifique]. Cahier des normes pédagogiques nationales cycle ingénieur 2014

[15] Bejan, S. A., Janatuinen, T., Jurvelin, J., Klöpping, S., Malinen, H., Minke, B., \& Vacareanu, R. (2015). Quality assurance and its impact from higher education institutions' perspectives: methodological approaches, experiences and expectations. Quality in Higher Education, 21(3), 343371.

[16] Bargerstock, A. S., \& Richards, S. R. (2015). Case study: application of DMAIC to academic assessment in higher education. Quality Approaches in Higher Education, 6(2), 31-40.

[17] Robinson, M., \& Yorkstone, S. (2014). Becoming a Lean University: the case of the University of St Andrews. Leadership and Governance in Higher Education: Handbook for Decision-Makers and Administrators.

[18] Mazumder, Q. H. (2014, June). Applying six sigma in higher education quality improvement. In American Society for Engineering Education.

[19] Prasad, K. D., Subbaiah, K. V., \& Padmavathi, G. (2012). Application of Six Sigma methodology in an engineering educational institution. International Journal of Emerging Sciences, 2(2), 210-221.

[20] Brady, M. P. (2013). Multiple roles of student and instructor in university teaching and learning processes. The International Journal of Management Education, 11(2), 93-106.

[21] Akinyele, S. T. (2010). Customers: Identifying the needs in higher education. Educational Research, $1(7), 210-218$

[22] Brandenburg, H., \& Wojtyna, J. P. (2006). L'approche processus: mode d'emploi. Editions Eyrolles.

[23] Maurice, P. I. L. L. E. T. (2004). Six Sigma: comment l'appliquer. Organisation 


\section{Authors}

\section{Amine HADEK}

- PhD Student, Research team on Engineering Education at ENSEM,Engineering Research Laboratory (LRI),Hassan II University Casablanca, Morocco.

- Specialist of bill of materials management and car homologation at Altran, Morocco

- Mechanical Engineer in 2014, ENSEM

\section{Hind CHAIBATE}

- PhD Student, Research team on Engineering Education at ENSEM, Engineering Research Laboratory (LRI), Hassan II University Casablanca, Morocco.

- Industrial Engineer in 2015, ENSEM

\section{Soumia BAKKALI}

- PhD in micro-electronic from the HassanII University Casablanca in 1996. • Since 1997, professor at ENSEM.

- Member of research team on Engineering Education and member of the system architecture team at ENSEM, Hassan II University, Casablanca, Morocco.

- She gives the following courses: analog electronic, fiber optic telecommunication and physic of semiconductor.

\section{Souad AJANA}

- Since 1987, professor at ENSEM, Hassan II University Casablanca, Morocco.

- Pedagogical Skills in Industrial Hydraulics, Control and Measurement Techniques and Materials Resistance $\bullet$ Head of the Laboratory of Metrology at ENSEM

- Fields of research: Hybrid bearings in laminar and turbulent regimes Ex Member of the Rheology and Plastic Materials Research team Since 2014, Creation and Head of the research team on engineering education (ERFSI) attached to the Engineering Research Laboratory (LRI) • In 1987, PhD in Fluid Mechanics, Lille 1 University
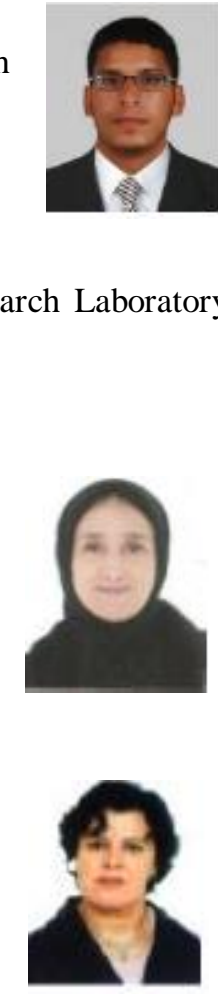